\title{
Stereoselective Synthesis of Medium-Sized Cyclic Ethers by Sequential Ring-Closing Metathesis and Tsuji-Trost Allylation
}

\author{
James Skardon-Duncan, Michael Sparenberg, Alexandre Bayle, Sam Alexander, and J. Stephen Clark*i) \\ WestCHEM, School of Chemistry, University of Glasgow, Joseph Black Building, University Avenue, Glasgow G12 8QQ, United \\ Kingdom
}

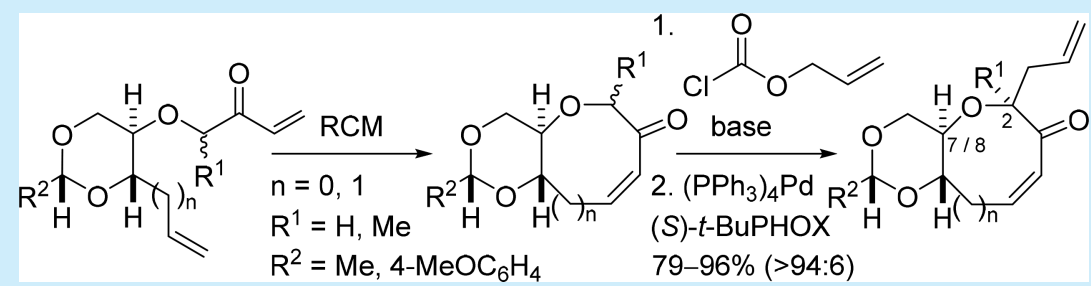

ABSTRACT: Fully functionalized medium-sized cyclic ethers, of the type found in fused polyether natural products, have been prepared by sequential ring-closing diene metathesis, conversion of the resulting cyclic enone into an allylic enol carbonate, and Tsuji-Trost allylation using a chiral palladium complex. Very high levels of diastereocontrol, favoring the diastereomer in which there is a cis relationship between the allyl group at C-2 of the medium-ring ether and the substituent at C-7/C-8, are obtained in cases where catalyst control and substrate control are matched.

$\mathrm{M}$ edium-sized cyclic ethers occur frequently as subunits in marine natural products. Fused polycyclic ether natural products such as CTX-3C (1) (Figure 1) have structures that

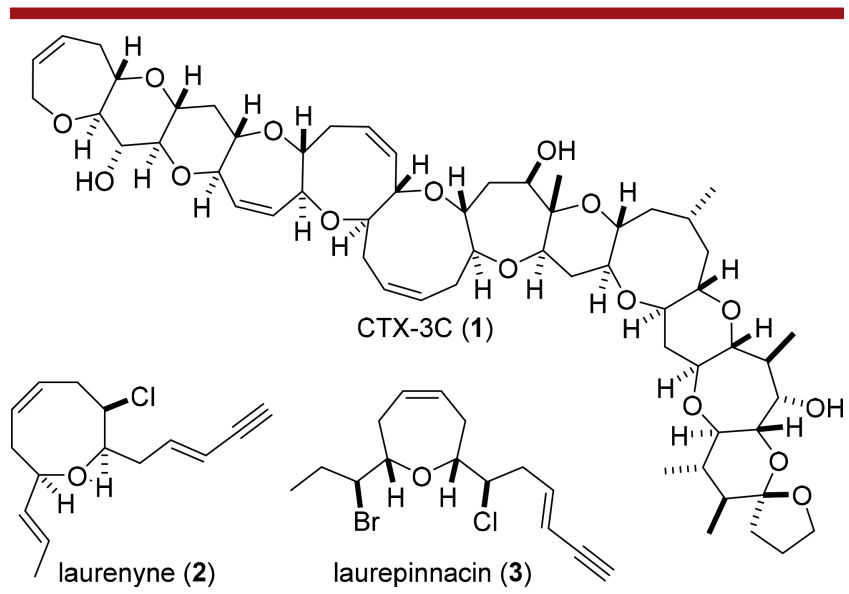

Figure 1. Examples of marine natural products that contain mediumsized cyclic ethers.

contain an abundance of both saturated and unsaturated medium-sized cyclic ethers ranging in size from seven to nine. ${ }^{1}$ In addition, many smaller monocyclic marine natural products possessing seven-, eight- and nine-membered rings [e.g., laurenyne (2) and laurepinnacin (3)], have been isolated from marine sources. ${ }^{2}$

As part of our longstanding research program directed toward the synthesis of marine fused polyether natural products of the ciguatoxin and gambieric acid classes, ${ }^{3}$ we are exploring novel methods for the rapid and stereoselective synthesis of highly functionalized medium-sized cyclic ethers and applying them to the efficient preparation of fused polycyclic ether frameworks by iterative ring construction. ${ }^{4}$ In previous work, we employed an asymmetric variant of the Tsuji-Trost allylation reaction to couple highly functionalized fragments and thereby assemble the tetracyclic A-D fragment of the gambieric acids (Scheme 1). ${ }^{5}$ In this case, treatment of carbonate 4 with a palladium complex of the $(S)$ - $t$-BuPHOX ligand afforded the rearranged product 5 in good yield with a high level of diastereocontrol.

The success of the fragment coupling reaction prompted us to explore the Tsuji-Trost allylation reaction as a general method for the synthesis of fully functionalized seven- and

Scheme 1. Asymmetric Tsuji-Trost Allylation Reaction Applied to Polyether Fragment Coupling

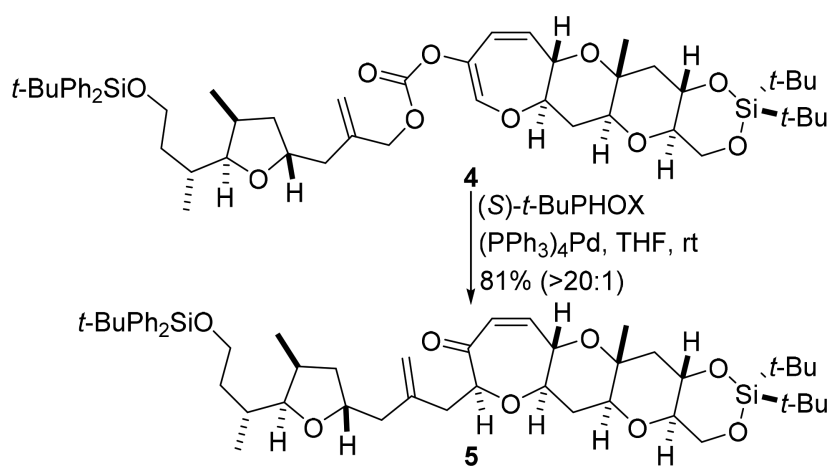

Received: April 6, 2018

Published: April 20, 2018 
eight-membered cyclic ether building blocks and for the construction of fused polycyclic ether arrays by iterative construction of cyclic ethers (Scheme 2). We planned to

Scheme 2. Stereoselective Iterative Synthesis of Fused Polyethers

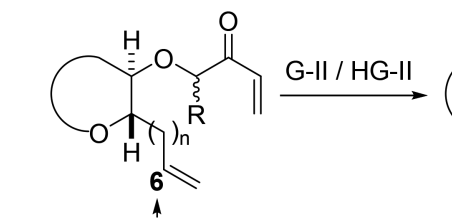

1. reduction

2. alkylation:

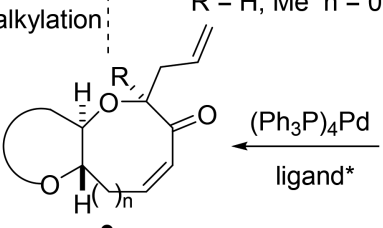

9

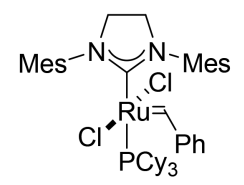

G-II

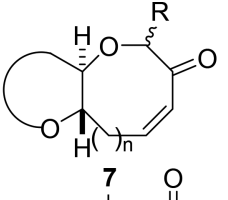<smiles>[TeH]</smiles><smiles>O=C(Cl)OC/C=C\COC(=O)O[Na]</smiles><smiles>[R]C1=C(OC(=O)OCC=C)C=CCC2OCCCC[C@]12O</smiles>

8

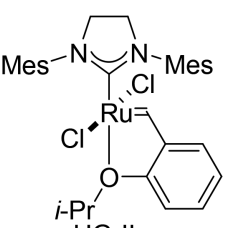

HG-II

perform ring-closing metathesis $(\mathrm{RCM})^{7}$ on enone 6 using either the Grubbs second-generation catalyst (G-II) or the Hoveyda-Grubbs second-generation catalyst (HG-II) and then convert the resulting cyclic enone 7 into the allylic enol carbonate 8 by treatment with base and allyl chloroformate. A stereoselective Tsuji-Trost allylation reaction would then be used to convert 8 into the $C$-allylated product 9 . Subsequent carbonyl reduction and functionalization would then allow the RCM and allylation sequence to be repeated.

In previously published work, ${ }^{4 \mathrm{f}}$ we have shown that hydrazones prepared from enones such as $7(\mathrm{R}=\mathrm{H})$ can be alkylated, but the levels of diastereocontrol are modest, and subsequent epimerization is required to deliver an acceptable level of diastereocontrol. An additional step is required to regenerate the ketone, and modest yields are obtained for the four-step sequence of hydrazone formation, alkylation, epimerization, and hydrazone cleavage, which detracts from the utility of the method.

The seven-membered cyclic ether substrates required for the Tsuji-Trost allylation reaction were prepared as shown in Scheme 3. The first substrate, oxepenone 11, was prepared from chiral-pool-derived alcohol $\mathbf{1 0}$ by the use of our published three-step route. ${ }^{8}$ Preparation of enone 15, the methylsubstituted analogue of oxepenone 11, began with alkylation of alcohol 10 with ethyl 2-bromopropionate to give ether $\mathbf{1 2}$. Reaction of the ethyl ester with methylenetriphenylphosphorane afforded stabilized ylide 13 directly, and subsequent reaction with formaldehyde delivered enone $14 .^{9}$ Treatment of the enone with the G-II resulted in ring closure to produce enone $\mathbf{1 5}$ as a diastereomeric mixture. ${ }^{10}$

Eight-membered cyclic ether precursors for the Tsuji-Trost allylation reaction were prepared from the known alcohol $16^{4 \mathrm{~b}}$ as shown in Scheme 4. Alkylation of $\mathbf{1 6}$ with chloroketophosphorane $17^{11}$ afforded phosphonium ylide 18, and subsequent reaction with formaldehyde delivered enone 19 (Scheme 4). ${ }^{12}$

Scheme 3. Synthesis of Allylation Precursors 11 and 15<smiles>C/C=C\[C@H]1O[C@@H](C)OC[C@@H]1O</smiles>

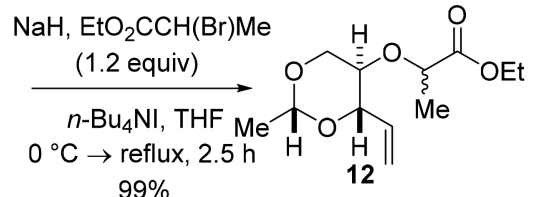

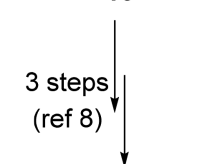
$99 \%$ $\mid \begin{aligned} & {\left[\mathrm{Ph}_{3} \mathrm{PCH}_{3}\right]^{+} \mathrm{Br}^{-}} \\ & (1 \text { equiv) } \\ & n \text {-BuLi ( } 2 \text { equiv }) \\ & \mathrm{THF},-78^{\circ} \mathrm{C} \rightarrow \mathrm{rt}\end{aligned}$<smiles>O=C1C=C[C@H]2OCOC[C@H]2OC1</smiles><smiles>C=CC1(OC(C(=O)P)C(=O)C=P)OC(C)OCC1C</smiles>

$\mathrm{CH}_{2} \mathrm{O}$ aq, $\mathrm{Et}_{2} \mathrm{O}$ $\mathrm{pH} 7$ buffer rt, $2 \mathrm{~h}$ $91 \%$ ( 2 steps)<smiles>C=CC(=O)C(C)OC1COC(C)OC1(C=C)OC1OC2COC(C)OC2(C)C=CC1=O</smiles>

Scheme 4. Synthesis of Allylation Precursors 21 and 22

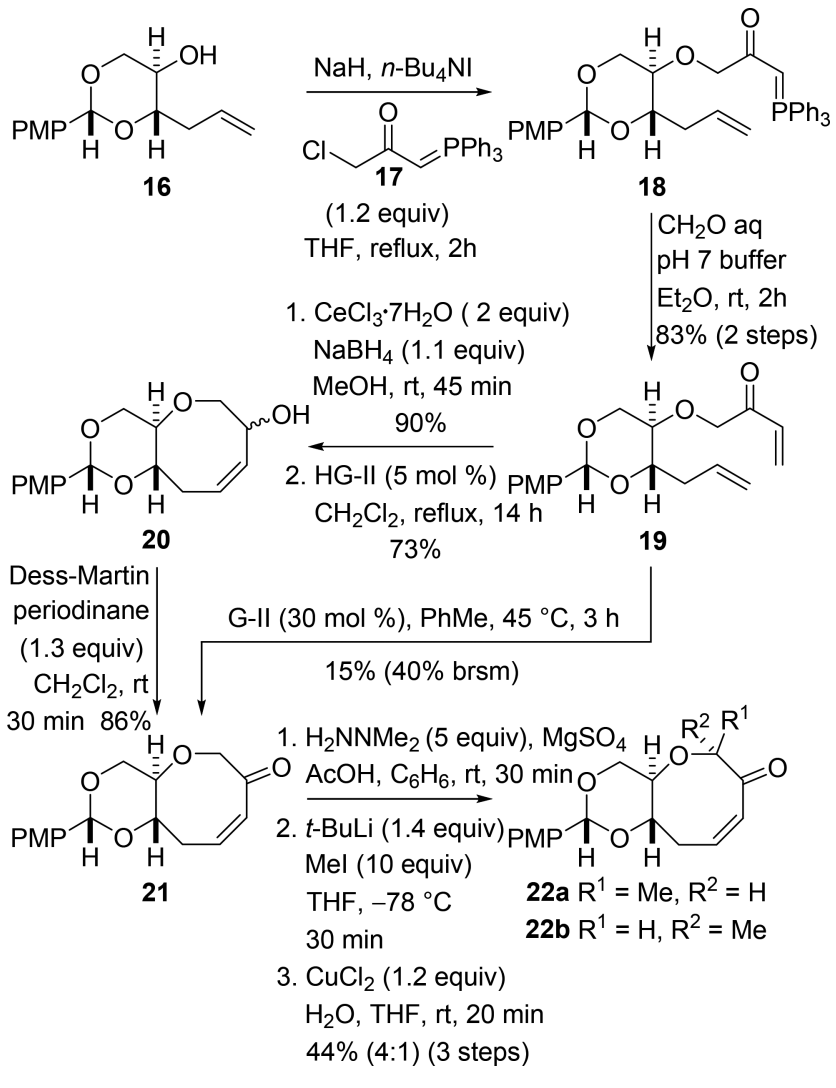

Direct RCM of 19 using G-II was problematic because a high catalyst loading ( $30 \mathrm{~mol} \%$ ) was required, and both the level of conversion and yield of the cyclized product $\mathbf{2 1}$ were low. To circumvent these problems, the enone was reduced to give a mixture of diastereomeric allylic alcohols, and RCM was performed thereafter to give a diastereomeric mixture of the 
cyclized product 20 in good yield. Oxidation of alcohols 20 afforded the required oxocenone $\mathbf{2 1}$, and this compound was methylated by sequential dimethylhydrazone formation, deprotonation, alkylation, and hydrazone cleavage to give a diastereomeric mixture (4:1) of enones 22 a and 22 b in $44 \%$ yield. ${ }^{13}$ The mixture of diastereomers was used directly to generate the enol carbonate required for the Tsuji-Trost allylation reaction.

Enones 22a and 22b were also prepared by the more direct route shown in Scheme 5. Alcohol 16 was alkylated with ethyl

Scheme 5. Alternative Route for the Synthesis of Allylation Precursor 22<smiles>C=CCC1([18F])OCC(O)C(P)(P)O1</smiles>

$\mathrm{NaH}, n-\mathrm{Bu}_{4} \mathrm{NI}$ $\mathrm{EtO}_{2} \mathrm{CCH}(\mathrm{Br}) \mathrm{Me}$

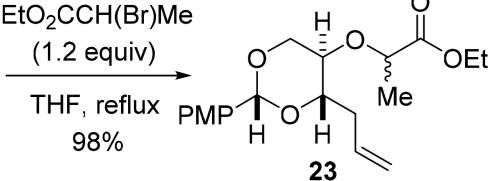
23

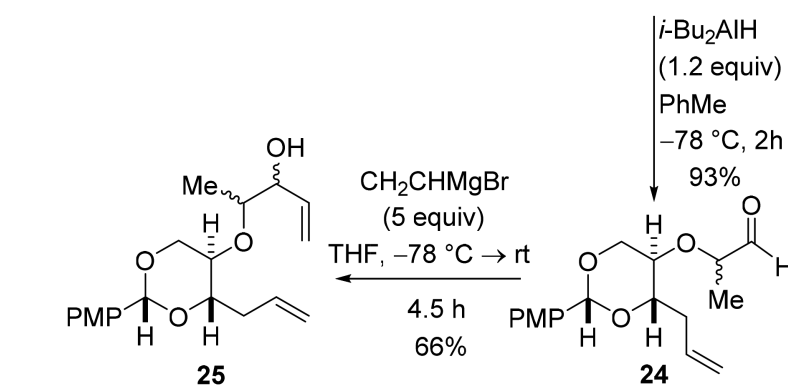

1. HG-II (3 mol \%)

$\begin{array}{ll}\mathrm{CH}_{2} \mathrm{Cl}_{2} \text {, reflux } \\ 18 \mathrm{~h} & 87 \%\end{array}$

2. Dess-Martin

periodinane

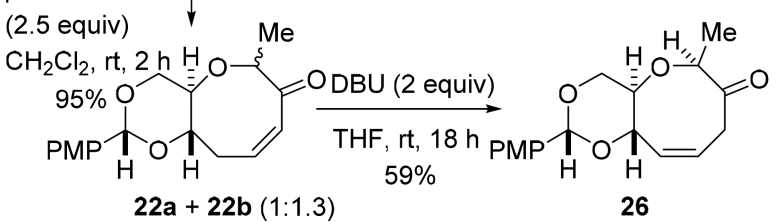

2-bromopropionate, and reduction of the resulting ester $\mathbf{2 3}$ using DiBAl-H produced a diastereomeric mixture of aldehydes 24. Reaction of the aldehydes with vinylmagnesium bromide afforded a mixture of the four diastereomeric alcohols 25, and subsequent RCM produced an isomeric mixture of the oxocenes in excellent yield. Oxidation of the alcohols then afforded enone 22 as a mixture of diastereomers $(\mathbf{a}: \mathbf{b}=1: 1.3)$. Attempts to perform DBU-mediated epimerization of the diastereomeric mixture to give predominantly diastereomer 22a resulted in deconjugation of the enone to produce ketone $\mathbf{2 6}$ as a single diastereomer, as judged by ${ }^{1} \mathrm{H}$ NMR analysis. ${ }^{14}$

Preparation of the enone substrates 11, 15, 21, and 22 allowed the Tsuji-Trost allylation reactions to be explored. Enones 11 and 15 were converted into enol carbonates 27 and 28 in excellent yield by deprotonation with sodium hexamethyldisilazide and $O$-acylation of the resulting enolates with allyl chloroformate (Scheme 6). ${ }^{5}$ Highly stereoselective Tsuji-Trost allylation reactions were then accomplished by exposure of enol carbonates 27 and $\mathbf{2 8}$ to the palladium complex of (S)-t-BuPHOX (29) (Scheme 6 and Table 1). In the case of enol carbonate 27, ketone 32 was obtained in $96 \%$ yield with a $>97: 3$ preference for diastereomer 32a (entry 1,
Scheme 6. Stereoselective Allylation of Oxepenones 11 and 15

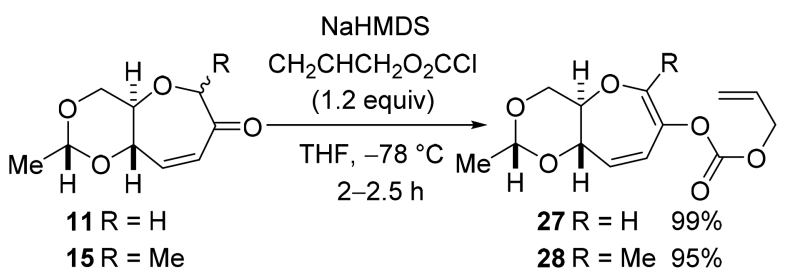

$\left(\mathrm{Ph}_{3} \mathrm{P}\right)_{4} \mathrm{Pd}(5 \mathrm{~mol} \%)$

ligand $(12.5 \mathrm{~mol} \%)$

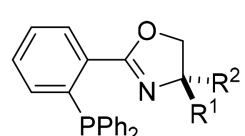

$29 \mathrm{R}^{1}=\mathrm{H}, \mathrm{R}^{2}=t-\mathrm{Bu}$

$30 \mathrm{R}^{1}=t-\mathrm{Bu}, \mathrm{R}^{2}=\mathrm{H}$

$31 R^{1}, R^{2}=M e$

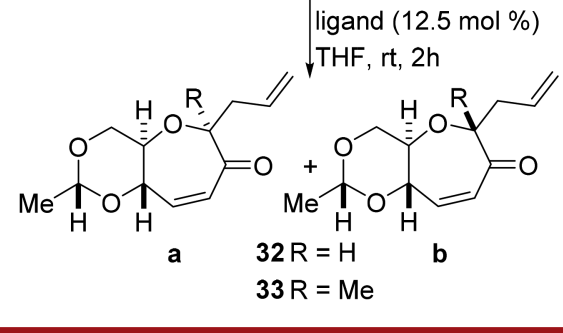

Table 1. Palladium-Mediated Rearrangement of Allylic Enol Carbonates 27 and 28

\begin{tabular}{cccccc} 
entry & substrate & ligand & product & a:b ratio & yield $(\%)^{b}$ \\
\hline 1 & $\mathbf{2 7}$ & $\mathbf{2 9}$ & $\mathbf{3 2}$ & $>97: 3$ & 96 \\
2 & $\mathbf{2 7}$ & $\mathbf{3 0}$ & $\mathbf{3 2}$ & $13: 87$ & 75 \\
3 & $\mathbf{2 7}$ & $\mathbf{3 1}$ & $\mathbf{3 2}$ & $69: 31$ & 92 \\
4 & $\mathbf{2 8}$ & $\mathbf{2 9}$ & $\mathbf{3 3}$ & $>97: 3$ & 95 \\
5 & $\mathbf{2 8}$ & $\mathbf{3 0}$ & $\mathbf{3 3}$ & $28: 72$ & 79 \\
6 & $\mathbf{2 8}$ & $\mathbf{3 1}$ & $\mathbf{3 3}$ & $87: 13$ & 88
\end{tabular}

${ }^{a}$ Diastereomeric ratios measured by ${ }^{1} \mathrm{H}$ NMR spectroscopy. ${ }^{b}$ Yields of products isolated after purification.

Table 1). ${ }^{15}$ When the reaction was repeated using the palladium complex of (R)-t-BuPHOX (30), a reversal in diastereoselectivity was observed, and a mixture of diastereomers (13:87) was obtained favoring diastereomer $\mathbf{3 2 b}$ (entry 2, Table 1). ${ }^{15}$ The Tsuji-Trost reaction performed using the palladium complex of the achiral PHOX ligand 31 delivered a 69:31 mixture of diastereomers favoring diastereomer 32a (entry 3, Table 1). Thus, substrate control favors formation of diastereomer 32a, and in the case of the reaction catalyzed by the palladium complex of $(S)-t$-BuPHOX (29), substrate and reagent control are matched. The same trend was observed in the case of methyl-substituted substrate 28; reaction with the catalyst prepared from (S)-t-BuPHOX (29) delivered the product 33 in excellent yield with a $>97: 3$ preference for diastereomer 33a (entry 4, Table 1). ${ }^{15}$ In the mismatched case, the palladium complex of $(R)-t$-BuPHOX $(30)$ produced enone 33 as a $28: 72$ mixture of diastereomers favoring diastereomer 33b (entry 5, Table 1), and when the reaction was performed using the palladium complex of the achiral ligand 31, the product 33 was obtained as an 87:13 mixture of isomers with diastereomer 33a predominating (entry 6, Table 1). ${ }^{15}$ These results reveal that substrate control favors the formation of diastereomer 33a. It is noteworthy that in the mismatched cases (entries 2 and 5, Table 1), the yields were significantly lower than those obtained from reactions in which the catalyst and substrate were matched (entries 1 and 4, Table 1).

The asymmetric Tsuji-Trost allylation reaction also proved to be highly effective for the preparation of fully functionalized oxocenes (Scheme 7 and Table 2). The enol carbonate precursors 34 and 35 were prepared from enones 21 and 22 by deprotonation and subsequent $\mathrm{O}$-acylation with allyl chlor- 
Scheme 7. Stereoselective Allylation of Oxocenones 21 and 22

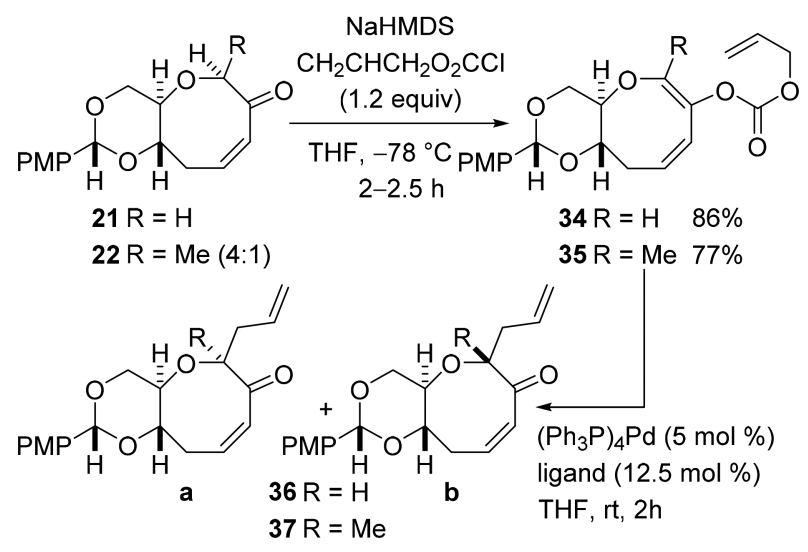

Table 2. Palladium-Mediated Rearrangement of Allylic Enol Carbonates 34 and 35

$\begin{array}{cccccc}\text { entry } & \text { substrate } & \text { ligand } & \text { product } & \text { a:b ratio } & {\text { yield }(\%)^{b}}^{b} \\ 1 & 34 & 29 & 36 & 94: 6 & 79 \\ 2 & 34 & 30 & 36 & 17: 83 & 73 \\ 3 & 34 & 31 & 36 & 66: 34 & 85 \\ 4 & 35 & 29 & 37 & >97: 3 & 81 \\ 5 & 35 & 30 & 37 & 55: 45 & 81 \\ 6 & 35 & 31 & 37 & 91: 9 & 86\end{array}$

${ }^{a}$ Diastereomeric ratios measured by ${ }^{1} \mathrm{H}$ NMR spectroscopy. ${ }^{b}$ Yields of products isolated after purification.

oformate. ${ }^{16}$ Treatment of enol carbonate 34 with the palladium complex prepared from the (S)-t-BuPHOX ligand (29) delivered the product 36 with a 94:6 preference for diastereomer 36a (entry 1, Table 2). ${ }^{15}$ In contrast, the mismatched pairing of substrate 34 with the palladium complex of the $(R)-t$-BuPHOX ligand (30) produced a 17:83 mixture of diastereomers favoring diastereomer $\mathbf{3 6} \mathbf{b}$ (entry 2, Table 2). ${ }^{15}$ Diastereomers $36 \mathrm{a}$ and $\mathbf{3 6 b}$ were produced in a ratio of $66: 34$ when an the palladium complex of achiral ligand 31 was employed as the catalyst (entry 3, Table 2). A similar trend was observed with the methyl-substituted substrate 35 . In this case, the matched pairing of substrate and catalyst produced diastereomer 37a exclusively (entry 4, Table 2); the mismatched pairing of substrate and catalyst afforded a 55:45 mixture of isomers favoring diastereomer $37 \mathbf{a}$, and the achiral catalyst delivered a 91:9 isomer mixture with diastereomer 37 a as the major product.

The data in Tables 1 and 2 show that the methyl-substituted enol carbonates $\mathbf{2 8}$ and $\mathbf{3 5}$ exhibit greater intrinsic selectivity for the formation of diastereomers 33a and 37a than do the corresponding unsubstituted substrates 27 and 34 for diastereomers 32a and 36a. However, matched catalyst control is sufficient to ensure highly selective formation of all of the required products $32 \mathrm{a}, 33 \mathrm{a}, 36 \mathrm{a}$, and $37 \mathrm{a}$.

In summary, we have demonstrated that highly functionalized seven- and eight-membered cyclic ethers can be prepared efficiently by sequential diene RCM, enol carbonate formation, and Tsuji-Trost allylation using a chiral palladium complex. Exceptionally high levels of diastereocontrol can be achieved in cases where catalyst and substrate control are matched. The allylated products 32a, 33a, 36a, and $37 a$ are fully functionalized building blocks that can be used for the preparation of polycyclic ether arrays, including those possessing ring-junction methyl substituents, which are found in marine polyether natural products such as the ciguatoxins and gambieric acids.

\section{ASSOCIATED CONTENT}

\section{Supporting Information}

The Supporting Information is available free of charge on the ACS Publications website at DOI: 10.1021/acs.orglett.8b01082.

Experimental procedures for the preparation of compounds 12, 14, 15, 19-28, and 32-37 along with compound characterization data and copies of ${ }^{1} \mathrm{H}$ and ${ }^{13} \mathrm{C}$ NMR spectra (PDF).

\section{AUTHOR INFORMATION}

\section{Corresponding Author}

*E-mail: stephen.clark@glasgow.ac.uk. ORCID 0

\section{J. Stephen Clark: 0000-0003-3935-0377} Notes

The authors declare no competing financial interest.

\section{ACKNOWLEDGMENTS}

The authors gratefully acknowledge studentship funding from the University of Glasgow for A.B. and funding from the EPSRC to support M.S. (EP/P505534), S.A. (EP/M506539), and J.S.-D. (EP/M506539, EP/L50497X, and EP/M508056).

\section{REFERENCES}

(1) Yasumoto, T.; Murata, M. Chem. Rev. 1993, 93, 1897-1909.

(2) (a) Wanke, T.; Philippus, A. C.; Zatelli, G. A.; Vieira, L. F. O.; Lhullier, C.; Falkenberg, M. Rev. Bras. Farmacogn. 2015, 25, 569-587. (b) Zhou, Z.-F.; Menna, M.; Cai, Y.-S.; Guo, Y.-W. Chem. Rev. 2015, 115, 1543-1596.

(3) (a) Nakata, T. Chem. Rev. 2005, 105, 4314-4347. (b) Inoue, M. Chem. Rev. 2005, 105, 4379-4405.

(4) (a) Clark, J. S.; Kettle, J. G. Tetrahedron Lett. 1997, 38, 123-126.

(b) Clark, J. S.; Kettle, J. G. Tetrahedron Lett. 1997, 38, 127-130.

(c) Clark, J. S.; Hamelin, O. Angew. Chem., Int. Ed. 2000, 39, 372-374.

(d) Clark, J. S.; Kimber, M. C.; Robertson, J.; McErlean, C. S. P.; Wilson, C. Angew. Chem., Int. Ed. 2005, 44, 6157-6162. (e) Clark, J. S. Chem. Commun. 2006, 3571-3581. (f) Clark, J. S.; Conroy, J.; Blake, A. J. Org. Lett. 2007, 9, 2091-2094.

(5) Clark, J. S.; Romiti, F.; Sieng, B.; Paterson, L. C.; Stewart, A.; Chaudhury, S.; Thomas, L. H. Org. Lett. 2015, 17, 4694-4697.

(6) For examples of asymmetric Tsuji-Trost allylation reactions perfomed using $\mathrm{Pd}-\mathrm{PHOX}$ complexes, see: (a) Behenna, D. C.; Stoltz, B. M. J. Am. Chem. Soc. 2004, 126, 15044-15045. (b) McFadden, R. M.; Stoltz, B. M. J. Am. Chem. Soc. 2006, 128, 7738-7739. (c) Mohr, J. T.; Stoltz, B. M. Chem. - Asian J. 2007, 2, 1476-1491. (d) Enquist, J. A., Jr.; Stoltz, B. M. Nature 2008, 453, 1228-1231. (e) Liu, Y.; Han, S.-J.; Liu, W.-B.; Stoltz, B. M. Acc. Chem. Res. 2015, 48, 740-751.

(7) For early examples of the application of RCM reactions to the synthesis of medium-sized cyclic ethers published by other research groups, see: (a) Fu, G. C.; Grubbs, R. H. J. Am. Chem. Soc. 1992, 114, 5426-5427. (b) Fu, G. C.; Nguyen, S. T.; Grubbs, R. H. J. Am. Chem. Soc. 1993, 115, 9856-9857. (c) Miller, S. J.; Kim, S.-H.; Chen, Z.-R.; Grubbs, R. H. J. Am. Chem. Soc. 1995, 117, 2108-2109. (d) Crimmins, M. T.; Choy, A. L. J. Org. Chem. 1997, 62, 7548-7549. (e) Crimmins, M. T.; Choy, A. L. J. Am. Chem. Soc. 1999, 121, 5653-5660. (f) Crimmins, M. T.; Emmitte, K. A. Org. Lett. 1999, 1, 2029-2032.

(g) Delgado, M.; Martín, J. D. J. Org. Chem. 1999, 64, 4798-4816.

(h) Crimmins, M. T.; Emmitte, K. A. Synthesis 2000, 2000, 899-903. 
(i) Lee, C. W.; Grubbs, R. H. J. Org. Chem. 2001, 66, 7155-7158. (j) Maeda, K.; Oishi, T.; Oguri, H.; Hirama, M. Chem. Commun. 1999, 1063-1064. (k) Rainier, J. D.; Allwein, S. P.; Cox, J. M. Org. Lett. 2000, 2, 231-234. (l) Prasad, K. R. K.; Hoppe, D. Synlett 2000, 2000, 1067-1069. (m) Hirama, M.; Oishi, T.; Uehara, H.; Inoue, M.; Maruyama, M.; Oguri, H.; Satake, M. Science 2001, 294, 1904-1907. (n) Allwein, S. P.; Cox, J. M.; Howard, B. E.; Johnson, H. W. B.; Rainier, J. D. Tetrahedron 2002, 58, 1997-2009.

(8) Clark, J. S.; Grainger, D. M.; Ehkirch, A. A.-C.; Blake, A. J.; Wilson, C. Org. Lett. 2007, 9, 1033-1036.

(9) (a) Wittig, G.; Schöllkopf, U. Chem. Ber. 1954, 87, 1318-1330. (b) Baldoli, C.; Licandro, E.; Maiorana, S.; Menta, E.; Papagni, A. Synthesis 1987, 288-290.

(10) For early examples of RCM reactions involving enones, see: (a) Krikstolaitytè, S.; Hammer, K.; Undheim, K. Tetrahedron Lett. 1998, 39, 7595-7598. (b) Paquette, L. A.; Efremov, I. J. Am. Chem. Soc. 2001, 123, 4492-4501. (c) Boiteau, J.-G.; Van de Weghe, P.; Eustache, J. Org. Lett. 2001, 3, 2737-2740.

(11) Hudson, R. F.; Chopard, P. A. J. Org. Chem. 1963, 28, 24462447.

(12) (a) Cossy, J.; Taillier, C.; Bellosta, V. Tetrahedron Lett. 2002, 43, 7263-7266. (b) Taillier, C.; Hameury, T.; Bellosta, V.; Cossy, J. Tetrahedron 2007, 63, 4472-4490.

(13) The stereochemical assignments for $\mathbf{2 2} \mathbf{a}$ and $\mathbf{2 2 b}$ were made on the basis of NMR analysis. In the case of enone 22a, a significant NOE was observed between the proton attached to the methyl-bearing carbon and the proton attached to the other carbon of the ether linkage in the eight-membered ring.

(14) For examples of deconjugation of enones in related eightmembered cyclic ethers, see: (a) Watanabe, K.; Suzuki, M.; Murata, M.; Oishi, T. Tetrahedron Lett. 2005, 46, 3991-3995. (b) Ahn, J.; Lim, C.; Yun, H.; Kim, H. S.; Kwon, S.; Lee, J.; Lee, S.; An, H.; Park, H.; Suh, Y.-G. Org. Lett. 2017, 19, 6642-6645.

(15) Stereochemical assignments for compounds $32 \mathrm{a} / \mathbf{b}, 33 \mathbf{a} / \mathbf{b}, 36 \mathbf{a} /$ $\mathbf{b}$, and $37 \mathbf{a} / \mathbf{b}$ were confirmed on the basis on NMR analyses (NOESY) performed in $\mathrm{CDCl}_{3}$ and/or $\mathrm{C}_{6} \mathrm{D}_{6}$. NOEs were observed between protons across the medium-ring ether linkage in the case of 32a and 36a and between the proton and the methyl group across the medium-ring ether linkage in the case of 33a and 37a. NOEs were not observed for the corresponding diastereomeric compounds $32 \mathbf{b}, \mathbf{3 3 b}$, $36 \mathbf{b}$ and $\mathbf{3 7 b}$.

(16) The diastereomeric ratio of enone $\mathbf{2 2}$ had a significant influence on the yield of enol carbonate 35 . Good yields were obtained when the enone enriched in isomer 22a (4:1) was used. The yield of enol carbonate 35 was significantly lower when material containing a higher proportion of isomer $\mathbf{2 2} \mathbf{b}$ was used. In this case, deprotonation of the enone at the $\gamma$-position and enolate trapping with allyl chloroformate delivered the regioisomeric enol carbonate. This observation suggests that the proton on the carbon adjacent to the carbonyl group in diastereomer 22b (C-2) is less accessible to the base than that in diastereomer 22a. This phenomenon was not observed in the case of enone 15, where both diastereomers reacted to give enol carbonate 28 in good yield. 